\section{O êxtase da comunicação no pensamento francês contemporâneo}

\section{RESUMO}

0 pensamento francês contemporâneo é hoje um dos principais produtores de teorias da comunicação na introdução da era pós-moderna. Jean Baudrillard, Paul Virilio, Henry-Pierre Jeudy, Edgar Morin, Michel Maffesoli, Lucien Sfez, Régis Debray, Jacques Derrida, Ignacio Ramonet, JeanFrançois Lyotard e Pierre Lévy expressam um pensamento comuni-cacional de vanguarda, inovador e surpreendente e que, apesar de ostentar um caráter ecumênico por suas diversas matrizes filosóficas, epistemológicas e metodológicas, entroniza a comunicação como o fenômeno central da era pós-moderna.

\section{ABSTRACT}

Contemporany French thought is today one of the main producers of communication theories in the postmodern age. Jean Baudrillard, Paul Virilio, Henry-Pierre Jeudy, Edgar Morin, Michel Maffesoli, Lucien Sfez, Regis Debray, Jacques Derrida, Ignacio Ramonet, Jean-François Lyotard e Pierre Lévy, all of them express an avant-garde thinking about communication which is innovative and astonishing In spite of its ecumenic form, due to its several philo-sophical, epistemological and methodological roots, it exalts the communication as the central phenomenon of the postmodern age

\section{PALAVRAS-CHAVE (KEY WORDS) \\ - Comunicação (Communication) \\ - Mídia (Media) \\ - Pós-Modernidade (Postmodernity)}

\section{Leandro Marshall}

Prof. UEPG/PR - Doutorando em Comunicação PUC/RS
A FERTILIDADE, A ORIGINALIDADE e o brilhantismo das obras sociológicas $\mathrm{e}$ filosóficas produzidas hoje na França nos autorizam a apontar o pensamento fancês contemporâneo como uma das principais usinas intelectuais do mundo na leitura e interpretação dos fenômenos comunicacionais midiáticos nesta era pósmoderna ${ }^{1}$. Um grupo amplo e heterogêneo de pensadores ${ }^{2}$, como Jean Baudrillard, Paul Virilio, Henry-Pierre Jeudy, Edgar Morin, Michel Maffesoli, Lucien Sfez, Régis Debray, Jacques Derrida ${ }^{3}$, Ignacio Samonet, Jean-François Lyotard e Pierre Lévy, vem expressando um pensamento comunicacional de vanuarda, inovador e surpreendente e que, apesar de sustentar um caráter ecumênico por suas diversas matrizes filosóficas, epistemológicas e metodológicas, tem entronizado a esfera da comunicação como fenômeno determinante na contemporaneidade cibertecnológica.

Este espectro de pensadores tem sido alojado, em parte, sob a rubrica da pósmodernidade e, em parte, sob a tutela do pós-estruturalismo, embora uma minoria tenha que ser enquadrada ainda em torno do pensamento moderno. De maneira geral, entretanto, esta legião francesa tem sido invariavelmente associada ao movimento pós-68, já que, em certo sentido, eles estariam (em sua maioria) empenhados em desconstruir e reconstruir os fundamentos das narrativas que se organizaram em torno da modernidade, agora no ambiente da pós-modernidade.

A verdade é que, de qualquer forma, para esta trupe de intelectuais franceses, integrantes de correntes que poderemos chamar de autônomas ou independentes 
(à exceção de um ou outro) e originários de distintas áreas do conhecimento, o fenômeno da comunicação tornou-se, de maneira direta ou indireta, uma espécie de leitmotiv dos fenômenos sociais, econômicos, políticos, tecnológicos e culturais da nova era, onde se formatam os discursos, os sentidos e as interações humanas, e onde se tecem as redes e as interfaces entre os diversos campos do conhecimento humano. $O$ consenso é de que a arena da comunicação midiática é a dimensão por onde operam e se imbricam as teias tecnológicas, estéticas ou econômicas da pós-modernidade, o que estaria hoje empurrando a humanidade para novas experiências em termos do saber, do sentir, do perceber e do fazer.

A perspectiva presente em suas análises trata a comunicação como fenômeno ou epifenômeno tangente em todos os processos culturais contemporâneos, malgrado, a seu modo, os olhares e os approachs teóricos desenvolvidos por cada um serem bastante diferenciados. De um lado, estão os radicalmente críticos, aqueles pessimistas com tom quase panfletário, que vislumbram dias sombrios com os cenários abertos pelo novo universo tecno-ciber-mass-midiático. Nestes, podemos incluir sobretudo as análises de Paul Virilio, Lucien Sfez e Ignacio Ramonet. Em lado oposto, encontram-se aqueles que antevêem possibilidades alvissareiras para a comunidade mundial, como Michel Maffesoli e Pierre Lévy. Há, entretanto, outros com clara ênfase frankfurtiana, como Henry Pierre-Jeudy, e aqueles que transportam ainda uma fé inconfessa nos desígnios e poderes da modernidade iluminista, como são os casos de Dominique Wolton e Edgar Morin.

A diretriz fundamental de todos estes scholars franceses, ao que parece, é sobretudo não seguir certezas inabaláveis em programas metodológicos, epistemológicos ou filosóficos. Todos, sem exceção, professam um caminho criado pelas suas próprias pegadas teóricas, construídas ao longo do convívio intelectual com a obra ou com o aprendizado direto com os grandes filósofos da humanidade.

Não podemos esquecer que a França é berço de René Descartes, inspirador do iluminismo, de Diderot e D'Alembert, baluartes do enciclopedismo, de JeanJacques Rosseau e Justus Saint-Simon, patronos do pensamento humanista, de August Comte, o criador do positivismo, de Emile Durkheim, o pai da sociologia científica, além de tantos outros pensadores como Montesquieu, Voltaire, Maquiavel, Montaigne, Sartre, Piaget e Braudel.

Não bastasse esta tradição teórica clássica na sociologia e na filosofia, que inspira hoje séquitos pelo mundo inteiro, os pensadores franceses contemporâneos também são tributários dos aportes inovadores de Michel Foucalt, Gilles Deleuze, Felix Guatarri, Louis Althusser, Roland Barthes, Michel de Certau, Gilbert Durant, Gaston Bachelard e Henri Lefevbre, além de Pierre Bordieu, falecido recentemente.

O berço do socialismo mundial, forjado a sangue em 1789, deu ao mundo a partir dos séculos XIX e XX uma tradição de novidade, vigor e vitalidade na reflexão crítica sobre os fenômenos da emergente indústria da comunicação. A partir do advento do telefone, do telégrafo, da fotografia e do cinema, no século XIX (em que muitos dos pioneiros também são franceses, como Joseph Nièpce, Daguerre e os irmãos Lumière), a exegese francesa passou a se preocupar em decifrar os avatares do novo mundo e do novo homem que estava a surgir, migrando seu foco paulatinamente para o impacto e os efeitos da indústria cultural. Gustave Le Bon e Gabriel Tarde foram alguns dos pioneiros a identificar os movimentos de massa e a força das multidões na transição da identidade do sujeito moderno, entendida por Ferdinand Saussure, em 1918, como a emergência de um universo de signos e simbologias, a reformarem as estruturas 
e as entranhas da sociedade industrial européia, o que foi interpretado como uma força de totalidade estrutural por Claude Lévi-Strauss e inspirou as interpretações psicológicas sobre a identidade e personalidade para Jean Piaget.

Enquanto a sociedade francesa vivia a Belle Époque e saboreava as delícias ofertadas pelos gadgets tecnológicos produzidos pelas engrenagens de Henry Ford, Fayol, Taylor, e desfrutava um cotidiano tecno-burocrático desenvolvimentista, energizado pela fé no progresso, o pensamento francês, mantendo a sua tradição atávica racionalista em vislumbrar, diagnosticar e antecipar as transformações nos movimentos sociais, passou a identificar a gestação de uma mutação que afetaria de maneira transcendente e imanente a psicologia e a sociologia das massas. $O$ homem gestado pela modernidade iluminista, conforme análises levantadas sobretudo na França, na Alemanha e na Inglaterra ao longo do século $X X$, estava se transformando em um produto da técnica (Martin Heidegger, Georg Simmel, Albert Camus), do sistema de objetos e da sociedade de consumo (Jean Baudrillard, Abraham Moles), em membro de uma sociedade contratual e não mais comunitária (Ferdinand Tönnies), elemento de uma vida totalitária (Hanna Arendt), joguete da estética da mercadoria (Wolfgang Fritz Haug), objeto dos aparelhos ideológicos (Louis Althusser), robô da racionalidade técnico-instrumental (Jürgen Habermas) e um agente passivo no enredamento do mundo pela indústria cultural (Theodor Adorno, Walter Benjamin, Max Horkheimer).

A interpretação dos processos sociais, culturais e econômicos identificava, cada vez mais, o enfraquecimento do sujeito diante do mundo em suas relações macro e microfísicas (Michel Foucault) e a emergência de uma sociedade fundada apenas nos valores do espetáculo e da banalização (Guy Debord). A crença desmedida na ciência e na técnica, o processo de secularização, a edificação de uma tecnocracia, a explosão do consumismo e a hegemonia crescente do valor de troca como signo social conduziram a sociedade e o sujeito a se transformarem em objetos da sua própria construção de realidade.

A ruptura com o pensamento moderno acabou acontecendo quando já era impossível abafar a inquietação acadêmica contra a crença institucionalizada e dogmática na ciência e com o conseqüente nascimento da crítica à chamada epistemologia da prova. Foram, sobretudo, Thomas Kuhn, com A Estrutura das Revoluções Científicas, Paul Feyerabend, com os seus Contra o Método e Adeus à Razão, e Jean-François Lyotard, com A Condição Pós-Moderna, que não somente demonstraram que as certezas científicas da era moderna estavam embasadas sobre evidências preliminares equivocadas, mas que a própria idéia de modernidade iluminista teria de ser superada.

Estas análises teóricas acabaram deflagrando inapelavelmente o processo de implosão da modernidade e abrindo o movimento de construção hermenêutica e culturalista de novas leituras, olhares e reflexões sobre a sociedade, sobre o novo homem e sobre os avatares históricos. Devido às obras de Kuhn, Feyerabend e Lyotard, o conhecimento acumulado hoje na modernidade é um patrimônio sub judice tanto quanto os métodos que compuseram as suas certezas.

A pós-modernidade, demarcada como tendo nascida ora com o movimento de contestação e rebeldia estudantil e social em maio de 1968, ora com a queda do Muro de Berlim e o início do fim do mundo socialista em 1989, ou ainda com o lançamento das bombas atômicas em Hiroshima e Nagasaki, em 1945, inaugurou uma época de liberdade intelectual, relatividade epistemológica, rejeição ao método, diferença, pluralidade, niilismo, hedonismo presenteísta e consumismo desenfreado, aspectos todos mergulhados 
em um ambiente livre em profusão tecnológica, em um frenético processo de midiatização e em uma agressiva onda de estetização do mundo. Entretanto, o traço fundamental, determinante e de natureza ubíqua, desta nova etapa histórica, subjacente a todos os processos sociais, acabou sendo o resgate dado aos valores da subjetividade humana.

A face mais acentuada da pósmodernidade parece ser hoje a natureza culturalista que investiga o sujeito e o seu imaginário, e as possibilidades desta relação diante da hierarquia da realidade, do conhecimento e da verdade. O mundo objetivo, da prova empírica e dos veredictos da ciência, dá lugar a uma perspectiva que enfatiza de maneira transcendental os aspectos da construção subjetiva da realidade, embora a questione e a critique.

Segundo as análises empreendidas pelas novas abordagens culturalistas pósmodernista e pós-estruturalista ${ }^{4}$, o centro do mundo é apreendido por um idealismo não mais objetivo mas agora fundamentalmente subjetivo, que costura a percepção entre o mundo sensível e o mundo inteligível. A nova perspectiva passa a empreender a crítica das teorias do conhecimento de raiz positivista e marxista, que abordavam o mundo a partir de uma visão materialista, além de fazer também a reavaliação das verdades estabelecidas pelo estruturalismo e pela fenomenologia hegeliana. Nisso, reformatam-se todas as perspectivas do sujeito e da sua interface com a realidade, empreendendo-se um tribunal das tecnologias do imaginário. O sentido deixa de se reduzir ao sujeito ou à composição das estruturas. O sujeito pós-moderno passa a ser examinado e compreendido em sua complexidade, em sua contingência e em sua singularidade.

O filósofo francês Christian Descamps, que reúne todos estes pensadores debaixo do guarda-chuva que ele denomina de "pensamento singular", indica que esta corrente diversa e multiforme de intelectuais "abre espaço para as diferenças" e "duvida da própria ideologia da ciência", procurando superar combinadamente os pensamentos de Marx, Freud e Nietzsche, além de Hegel. "Sem posição de superioridade, ela [a corrente] examina o princípio da universalidade das razões, as buscas de fundamento único ou final. (...) Literário, elegante em suas formas, este movimento praticou bastante os desvios, as desmontagens, os desperdícios, as decifrações." (DESCAMPS, 1991, p. 14) Nesta vertente, passa-se a exaltar as multiplicidades nãoglobalizantes e a derrubar uma a uma as máscaras da modernidade, mostrando que não existe uma verdade única, inabalável, pétrea, mas que tudo faz parte de uma polissemia de verdades.

Nesta nova vertente de pensamento, o texto dá lugar ao contexto e ao discurso, a realidade passa a aceitar a expansão de um espectro de virtualidade e simulação, o sujeito perde seu cetro, as sociedades incorporam as idéias de rede e de teias tecnológicas, os relógios modernos passam a ser ajustados pelas leis da dromologia, o estudo da superfície dá lugar à investigação dos subterrâneos da essência, os valores de uso e de troca são tragados pelo valor de signo, o consumismo torna-se uma patologia social, a análise da crescente mundialização é trocada pela abordagem de uma febril globalização financeira e tecnológica e o poder da mídia ganha ares de um verdadeira midiocracia, a merecer uma "disciplina científica" própria, talvez a midiologia.

Em maior ou menor grau, a intelectualidade francesa acabou se debruçando sobre um caldeirão de fenômenos culturais, sociais, econômicos e tecnológicos, com forte caráter contraditório, entre o místico, o mercadorismo e o esteticismo, entre o novo e o arcaico, entre o sagrado e o profano, entre o local e o global, entre o espaço e o tempo, entre o real e o virtual.

Antes de tudo, entretanto, os franceses têm procurado fugir da "miopia" 
científica do empirismo, da objetividade e da prova, para não cair nas mesmas antinomias da modernidade positivista. Segundo Descamps, os pensadores franceses "examinam noções de economia, de eficácia, de verdade única, todas as categorias 'eternas' de um pseudo homo sapiens sem incerteza ou indeterminação. Para eles, o mito, o afeto e o delírio não são obstáculos, mas possíveis fermentos de conhecimento" (DESCAMPS, 1991, p. 14).

Um dos pioneiros nesta nova linhagem culturalista foi, sem dúvida, o filósofo francês Guy Debord, que embora tenha seu pensamento muitas vezes associado à visão moderna de natureza marxista, pode certamente ser considerado como um dos visionários da era pós-moderna. Foi ele que, em 1967, antes da eclosão das revoltas estudantis e da revolução de costumes detonada pelos franceses no mês de maio de 68, vislumbrou e anunciou a emergência de uma força social autocrática de dominação mercantil, alienação coletiva, estetização e do fetichismo da mercadoria, que estaria envelopando as mentes e os corpos em todas as suas interfaces sociais. A isto ele denominou de espetáculo e qualificou como uma lógica que operaria o discurso ininterrupto da mercadoria, uma espécie de monólogo laudatório, e que estaria atuando como uma "segunda natureza", com suas leis fatais, sobre o caráter da relação dos homens.

"O espetáculo é o momento em que a mercadoria ocupou totalmente a vida social. Não apenas a relação com a mercadoria é visível, mas não se consegue ver nada além dela: o mundo que se vê é o seu mundo. A produção econômica moderna espalha, extensa e intensivamente, sua ditadura. Nos lugares menos industrializados, seu reino já está presente em algumas mercadorias célebres e sob a forma de dominação imperialista pelas zonas que lideram o desenvolvimento da produtividade. Nessas zonas avançadas, o espaço social é invadido pela superposição contínua de camadas geológicas de mercadorias." (DEBORD, 1967, p. 31)

O pensador francês, discípulo confesso da teoria social crítica e da doutrina materialista, publicou suas idéias na obra já clássica $A$ Sociedade do Espetáculo (1967), onde pôde expor seu pensamento em 221 teses, escritas com o estilo aforístico. Guy Debord professou em sua análise uma espécie de libelo contra a dominação econômica capitalista e contra o que ele interpretou como a constituição cristalina de um regime de falsificação total da vida humana. Para ele, "toda a vida das sociedade nas quais reinam as modernas condições de produção se apresenta como uma imensa acumulação de espetáculos. Tudo o que era vivido diretamente tornouse uma representação" (tese 01).

Em uma abordagem essencialmente filosófica, Guy Debord estabelece a dinâmica da dominação do mundo pelas mercadorias e a sua conseqüente dominação da consciência humana. Depois de ressaltar que o "espetáculo não é um conjunto de imagens, mas uma relação social entre pessoas, mediada por imagens" (tese 04), o pensador francês chega a afirmar que "o espetáculo é ao mesmo tempo o resultado e o projeto do modo de produção existente. Não é um suplemento do mundo real, uma decoração que the é acrescentada. É o âmago do irrealismo da sociedade real"(tese 06).

Debord observa que, sob todas as suas formas particulares, o espetáculo estaria constituindo hoje (na segunda metade do século $X X$ ), o próprio modelo de vida da sociedade. Nada escaparia a esta engrenagem miraculosa, fundada em torno da relação entre os seres, entre as coisas e entre as imagens e representações do mundo. A lógica totalitária do espetáculo estaria cimentada sob um imenso território de transcendência e imanência. A tese 08 
é afirmativa desta mentalidade ao declarar que "a realidade surge no espetáculo e o espetáculo é real".

O espetáculo dominaria a objetividade e a subjetividade, o mundo presente e o mundo ausente, a verdade e a falsidade. $\mathrm{Na}$ tese 09, ele observa que "no mundo invertido, a verdade é um momento do que é falso". Na tese 34, expressa que "o mais importante é o mais oculto" e, na tese 37 , estipula que "o mundo presente e o mundo ausente que o espetáculo faz ver é o mundo da mercadoria dominando tudo o que é vivido".

Embora toda a sua obra seja baseada apenas em uma hermenêutica da sociedade, sem objeto ou campo de interpretação específico, senão o todo, o filósofo francês, que se declarava na época do lançamento da obra um "doutor em nada" e pensador radical, consegue abarcar visionariamente em sua exegese da sociedade uma universalidade de fenômenos que passaram a determinar intensivamente a dinâmica da pósmodernidade, em algumas de suas faces, somente alguns anos depois de suas análises. O foco debordiano antecipou com fidelidade a lógica da sociedade de consumo, o império da televisão e da imagem e os processos de simulação e de representação da vida real.

Apesar de, de certa maneira, fazer uma leitura da bolha de mercadorias criada pela inflação globalizante do capital empresarial e financeiro no mundo ocidental, Guy Debord estava querendo identificar e interpretar as forças econômicas sincrônicas e indicar utopicamente os caminhos para a transformação marxista da sociedade. Assim, em sua época, Debord nunca foi considerado um teórico pós-moderno, que tivesse agregado para a teoria da decomposição do mundo moderno. Sua análise, de cunho ostensivamente utópico, só agora, a partir do final do século $\mathrm{XX}$, começou a ser matizada como também uma manifestação embrionária do movimento pós-modernista, posto que nela já estariam em ebulição os fragmentos da erosão da modernidade e da eclosão de um império econômico hegemônico e naturalizado, com todos os princípios de uma era sem nome.

Hoje, verifica-se que a obra clássica de Guy Debord acabou sendo um prenúncio do que estaria por vir. A Sociedade do Espetáculo lançou uma semente de dúvida que passou a corroer o modelo de pensamento cartesiano. Poucos anos depois do trabalho de Debord, o francês Jean-François Lyotard protocolou no mundo acadêmico a sua tese sobre $A$ Condição Pós-Moderna (1979) ${ }^{5}$, traduzida no Brasil com o título de O Pós-Moderno, texto que imediatamente passou a ser considerado como o marco fundador da era pós-moderna, o divisor de águas dos paradigmas históricos.

Notabilizado como o arauto da pósmodernidade (enquanto poderíamos dizer que Guy Debord teria sido o seu profeta), foi o francês Jean-François Lyotard quem, em primeira mão, traçou uma radiografia da transformação do status do conhecimento nas sociedades avançadas no século $X X$ e prognosticou o fim da era da ciência positivista e do iluminismo moderno. Embora a intenção original fosse produzir apenas um relatório, A Condição PósModerna acabou se revelando como o próprio atestado de nascimento da pósmodernidade.

Nesta obra, feita às pressas sob encomenda pelo Conseil des Universités de Québec (Canadá), o pensador francês Lyotard anunciou o fim das metanarrativas que sustentaram o projeto da modernidade iluminista, como o marxismo, o positivismo, o freudismo, o cientificismo, etc. O pensador observou que as metanarrativas estavam ancoradas no discurso científico e que este não pode mais ser considerado suficiente para explicar e justificar os fenômenos da sociedade. O discurso científico não teria mais legitimidade e não seria mais eficaz, já que, além de ter se 
revelado como impotente para promover o bem-estar da humanidade, teria perdido sua força de unidade e seu caráter de método absoluto e infalível.

Para o sociológo francês, a ciência é apenas uma das tantas narrativas que embasam o processo de conhecimento e está longe de dar respostas definitivas para os fenômenos da realidade. A ciência teria se tornado uma expressão das relações de autoridade existentes nas comunidades científicas. Longe de produzirem descobertas acabadas, as ciências teriam se reduzido à queda-de-braço dos discursos. Ganha quem produzir o melhor discurso, quem conseguir sustentar seu argumento perante seus pares.

Desta forma, a ciência acabou se tornando no limiar do nascimento da era pós-moderna como "redes flexíveis de jogos de linguagem", onde o poder da ciência de atingir o conhecimento verdadeiro dá lugar à performatividade do sistema. Para Lyotard, "a função narrativa [da ciência] perde os seus functores, o grande herói, os grandes perigos, os grandes périplos e o grande objetivo. Ela dispersa-se em nuvens de elementos de linguagem narrativa, mas também denotativos, prescritivos, descritivos, etc., veiculando cada um consigo valências pragmáticas sui generis". (LYOTARD, 1979, p. 12) A linguagem tornase paralogia e o funcionamento do sistema passa a ser medido pela sua eficácia.

$\mathrm{Na}$ essência, o texto de Lyotard configura-se como uma punhalada mortal na crença do poder absoluto da ciência objetiva, ao mostrá-la, ao contrário, como constituída por uma esfera de natureza frágil e vulnerável, que se entrega à subjetividade humana. Nas entrelinhas desta crítica à ciência, podemos encontrar conseqüentemente uma pregação em torno do relativismo universal, embora fique claro que Lyotard relativiza o próprio relativismo. Em síntese, A Condição Pós-Moderna nos pergunta: $O$ que determina que um saber é possível de demonstração científica? Qual é a prova desta demonstração?
Qual é a prova da prova? Desta forma, o livro de Lyotard acaba demonstrando a impossibilidade do homem obter uma verdade absoluta, obtendo apenas as verdades relativas.

A obra do pensador francês antecipa também o caráter de ambivalência e ambigüidade da era pós-moderna, já que tudo passa a se resumir a jogos de linguagem, onde os homens usam a retórica para duelar suas idéias.

O processo de conhecimento e de busca da verdade não é invalidado, mas este acaba se tornando um jogo com regras validadas e legitimadas pelos jogadores. Freqüentemente, estas regras são alteradas, mudando-se as "verdades" relativas da ciência.

\section{Considerações finais}

Os teóricos franceses fundaram na pluralidade, na diversidade, no livrepensar e no ceticismo crítico as bases do que poderíamos começar a chamar de uma Escola Francesa de Comunicação. Esta seria certamente a escola mais heterogênea e antidogmática entre todas, já que nenhum de seus membros teria ou tem o propósito de formar uma Escola e nem ao menos aceitariam rótulos para o seu pensamento. Entretanto, do ponto de vista do objeto ou do campo estudado, é importante que se passe a esboçar os traços do que poderia naturalmente vir a ser uma corrente teórica, mesmo que diversa, pluralista, multi-epistemológica, transmetodológica e não determinista, para a investigação do universo da comunicação e da mass mídia.

O berço do pensamento político e cultural do mundo está herdando agora um patrimônio conceitual que atravessa em profundidade os fenômenos pósmodernos a ponto de estabelecer uma espécie de disciplina de comunicalogia, ou, para alguns, da própria comunicracia. Esta escola de pensamento (se nos 
permitirmos chamá-la assim) objetiva na imagem (Baudrillard, Jeudy), no signo (Saussure, Barthes, Bordieu), na técnica (Sfez, Virilio), na mídia (Debray), no sujeito (Foucault, Deleuze, Derrida, Guattari, Sfez), na comunidade virtual (Lévy) ou na comunidade identidária (Maffesoli), os novos modos de ser e de viver na contemporaneidade comunicacional.

O universo e a vida em comum reduziram-se na pós-modernidade a uma vida mediada pelos mecanismos, próteses ou meios de comunicação, na qual o que impera é uma constelação de signos e simbologias, formatando novas identidades, comunidades e virtualidades. Para os pósmodernos, a vida poderia estar deixando de ser real para tornar-se um exercício de simulação, de tautismo, de tecnificação, de próteses e de culto à imagem, embora há quem professe fé em um futuro auspicioso em torno de uma comunidade digital democrática, justa e igualitária.

O pensamento francês contemporâneo caracteriza-se sobremaneira pela refração a qualquer tipo de tradição ou a hibridismos acadêmicos. A maioria dos intelectuais vivos serve-se de um vasto manancial de conhecimentos acumulados mas procura construir caminhos novos no processo de organização da sua reflexão, insinuando, de certa forma, o nascimento de novos paradigmas teóricos. Assim são as idéias das máquinas desejantes de Deleuze e Guattari, a gramatologia de Derrida, a midiologia de Debray, o tempo das tribos e o presenteísmo de Maffesoli, o tautismo de Sfez, o pensamento único de Ramonet, a dromologia de Virilio, a era dos simulacros e simulações de Baudrillard.
Teorias da Comunicação no pensamento francês contemporâneo

\begin{tabular}{|c|c|c|}
\hline TEÓRICO & TEORIA & PARADIGMA HISTÓRICO \\
\hline Régis Debray & Midiologia & Pós-Modernidade \\
\hline Lucien Sfez & Tautismo & Pós-Modernidade \\
\hline Henni-Pierre Jeudy & Midiabzação generalizada & Pós-Modernidade \\
\hline Jean Baudrillard & Simulą̧̃o & Pós-Modernidade \\
\hline Edgar Monin & Pensamento Complexo & Modemidade \\
\hline Dominique Wroton & Televisão democrática & Modemidade \\
\hline Paul Vinilio & Dromologia & Pós-Modernidade \\
\hline $\begin{array}{l}\text { Gilles Deleuze e } \\
\text { Félix Guattari }\end{array}$ & Máquinas Desejartes & Pós-Estuturalismo \\
\hline Jacques Dernida & Gramatologia & Pós-Estruturalismo \\
\hline Pierre Bordieu & O poder simbólico & Modemidade \\
\hline Michel Maffesoli & $\begin{array}{l}\text { Presenteísmo, Tribalismo, } \\
\text { Nomadismo, Razão Sensivel }\end{array}$ & Pós-Modernidade \\
\hline Ignacio Ramonet & $\begin{array}{l}\text { Tirania da Comunic ação, } \\
\text { Pensamento Único }\end{array}$ & Pós-Modernidade \\
\hline Guy Dehord & A Sociedade-Espetáculo & Pós-Modernidade \\
\hline Jean-François Lyotard & Fim das Metanarrativas & Pós-Modernidade \\
\hline Pieme Lévy & Cibercultura democrática & Modemidade \\
\hline
\end{tabular}

Seja parte ou não de uma Escola ${ }^{6}$, os scholars franceses estão fazendo escola em livre-pensar, em erudição e em vanguarda. Alguns já destruíram os métodos modernos e levantaram as suas próprias propostas, enquanto outros estão empenhados em decupar os sentimentos e a sensibilidade de uma crítica que foge, como o diabo da cruz, das razões e das receitas da modernidade.

Esta característica, muitas vezes associada à prática do ensaísmo livre, à irreverência epistemológica e metodológica e à insubordinação aos cânones da ciência e da técnica, levou a trupe francesa a receber, em muitos momentos, o desdém ou o repúdio de coletivos intelectuais associados aos padrões da modernidade iluminista.

Em 1997, Alan Sokal, professor de física na Universidade de Nova York, e Jean Bricmont, professor de física na Universidade de Louvain, na Bélgica, publicaram em conjunto uma obra em que chamaram de impostores os teóricos Jacques Lacan, Julia Kristeva, Luce Irigaray, Bruno Latour, Jean Baudrillard, Gilles Deleuze, Felix Guattari e Paul Virilio. Os dois cientistas procuraram dinamitar os textos produzidos por estes teóricos franceses, acusandoos de produzir mistificações físicomatemáticas, disseminar um relativismo epistêmico absurdo e abusar no emprego 
de terminologias científicas, aplicadas, segundo eles, de maneira irresponsável. Resumidamente, Sokal e Bricmont acusam os franceses de:

1. Falar abundantemente de teorias científicas sobre as quais se tem, na melhor das hipóteses, uma idéia extremamente confusa. A tática mais comum é usar a terminologia científica (ou pseu-docientífica) sem se incomodar muito com o que as palavras realmente significam.

2. Importar conceitos próprios das ciências naturais para o interior das ciências sociais ou humanidades, sem dar a menor justificação conceitual ou empírica.

3. Ostentar uma erudição superficial ao atirar na cara do leitor, aqui e ali, descaradamente, termos técnicos num contexto em que eles são totalmente irrelevantes. (...)

4. Manipular frases e sentenças que são, na verdade, carentes de sentido. Alguns destes autores exibem uma verdadeira intoxicação de palavras, combinada com uma extraordinária indiferença para com seu significado. (SOKAL \& BRICMONT, 1999, p.18)

As críticas dos cientistas foram recebidas com um singelo silêncio pela inteligentzia francesa. Para eles, Sokal e Bricmont não passam de modernos com saudades do iluminismo e que ainda estão presos aos conceitos e às ferramentas teóricas da ciência e da técnica. Os dois cientistas é que seriam os verdadeiros impostores, ao não enxergarem e entenderem as mutações da humanidade.

O filósofo Christian Descamps observa que o pensamento francês pós-68 tinha ironicamente o objetivo de denunciar os "impostores" da modernidade, que, por sua vez, estes sim, tinham sustentado suas idéias na chamada superioridade da ciência. Aqui, na pós-modernidade, lembra Descamps, trata-se de entender que o mundo também é um relato, que tudo que narra é narrado: a arte, a ciência, a história. Tudo depende de interpretações e passa pela subjetividade.

De qualquer forma, o petardo contra o pensamento francês não foi suficiente para barrar o processo de fermentação erudita da análise crítica aos mídia. Palco de alguns do mais decisivos fenômenos da atualidade, como o ultracapitalismo, as privatizações, os fundamentalismos, os fluxos migratórios, o crescimento dos movimentos de direita, do consumismo, do tecnocentrismo e da midiatização das relações humanas, o olhar avant-garde pósmoderno francês prescruta com atenção os sinais de uma era a ser fundada, em tese, nos imperativos da subjetividade, do imaginário e da virtualidade.

O pensamento francês contemporâneo é, de fato, o mais analisado, o mais discutido e o mais amado e o mais odiado da sociologia mundial. Afinal, a França é a maternidade dos movimentos pós-modernista e pós-estruturalista, arregimentando legiões de novos apóstolos e novos discípulos em todo o mundo.

O teórico brasileiro Juremir Machado da Silva acredita que o valor da teoria francesa, essencialmente plural, está exatamente na potenciação de um pensamento de viés revolucionário, além da eleição dos fenômenos da cultura de massa, da indústria cultural, da mídia e da comunicação como fatores decisivos da realidade pós-moderna. "O mais interessante na babel francesa é que todos acertam e erram em proporções equilibradas. A comunicação é, ao mesmo tempo, fenômeno extremo, vínculo e cimento social, imagem 'reliante', fator de isolamento, produtora de 'tautismo', espetacularização do jornalismo e do mundo, cristalização da técnica que acelera a existência e suprime o espaço e o tempo, fator de interatividade, nova utopia, velha 
manipulação, meio, mensagem, suporte e vertigem de signos vazios." (MACHADO DA SILVA apud HOHLFELDT, MARTINO \& FRANÇA, 2001, p. 180) .

\section{Notas}

1 Este artigo pretende mapear e sumarizar o pensamento francês contemporâneo, contemplando pelo menos os principais intelectuais vivos de maior destaque no mundo acadêmico, para oferecer um esboço da sua interface com 0 universo da comunicação e da informação nesta era pós-moderna.

2 Este rol de intelectuais foi reunido de maneira aleatória, levando-se em conta apenas a dimensão e a repercussão que as suas obras têm causado sobre a sociologia e a filosofia desta época. Poderiam também ter sido citados teóricos de expressão, talvez com a mesma projeção e ressonância que os listados, como Eric Aliez, Alain Baudiou, Alain Minc, Michel Serres, Daniel Bougnoux, Michel Pecheux, Luce Irigaray, Jacques Genereux, Viviane Forrester, Dominique Mangueinau, Michel Houllebecq, Julia Kristeva, Joël de Rosnay, Gilles Lipovetsky, Jacques Rancière, Philippe Breton, Alain Touraine, Patrick Champagne, Bruno Latour e Armand Mattelart (que, embora tenha nascido na Bélgica, tem sua tradição intelectual gestada na França, com breve período no Chile)

3 Nascido na Árgelia, ex-possessão francesa, Jacques Derrida vive atualmente na França, onde tem desenvolvido suas reflexões e construído sua obra de natureza filosófica.

4 Sobre as diferenças entre Pós-Modernidade e PósEstruralismo a melhor obra é a de Michael Peters, traduzida para o português por Tomaz Tadeu da Silva, Pós-Estruturalismo e a Filosofia da Diferença: Uma Introdução. Belo Horizonte: Autêntica, 2000. De maneira sumária, a Pós-Modernidade pode ser compreendida como 0 movimento de transformação nas artes, ocorrida após o modernismo ou em reação a ele, ou, em sentido histórico e filosófico, como o questionamento e superação dos fundamentos científicos, positivos e iluministas da modernidade. 0 Pós-Estruturalismo é caracterizado pela tentativa de ultrapassar os pressupostos estruturalistas de Claude Lévi-Strauss (antropologia), Louis Althusser (marxismo), Jacques Lacan (psicanálise), Ferdinand
Saussure (lingüística) e Roland Barthes e Roman Jakobson (semiologia), questionando a idéia de estrutura, do significado transcendental e da centralidade do sujeito. De certo modo, o Pós-Estruturalismo tem sido associado como um compartimento da Pós-Modernidade, já que comunga com este os princípios de desconstrução e reconstrução da modernidade.

5 Apesar de Lyotard ter se notabilizado com a sua obra sobre a Pós-Modernidade, ele é autor de um conjunto vasto de reflexões ligadas ou à estética ou à política. Ele escreveu, por exemplo, Des dispositifs Pulsionales (1973), Économie Libidinale (1974), Discours, Figure (1974), La condition post-moderne (1979) e Le Différent (1983). O seu pensamento está alinhado com os trabalhos de Claude Lefort, Cornelius Castoriadis, P. Souyri, Jacques Derrida, Gilles Deleuze e Felix Guattari.

A falta de profundidade filosófica na A Condição Pós-Moderna não chegou a ser um aspecto que comprometesse ou colocasse sob quarentena a hipótese da ruptura de paradigmas entre duas eras. A hipótese Lyotardiana é considerada hoje como um verdadeiro manifesto "linguístico" que carrega, em seu bojo, os pressupostos da era pós-moderna. Visto como um retorno ao movimento estruturalista, a obra de Lyotard acabou influenciando gerações de intelectuais na França e no mundo inteiro, servindo como parâmetro epistemológico para a natureza da pós-modernidade.

6 Para o comunicólogo brasileiro Juremir Machado da Silva, discípulo de Maffesoli, a multiplicidade e a diversidade do pensamento francês não poderiam ser enquadradas dentro de uma escola. Para ele, a expressão "escola" seria um paradoxo para as contribuições francesas da atualidade. "Como homogeneizar o que é heterogêneo por definição e escolha? Como agrupar pensadores que sempre fizeram questão de combater-se? Como dar unidade ao que sempre buscou a diversidade? Como conectar o que nunca passou de simulação de rede? Como teorizar o que não se apresenta sob a forma de teoria? Como justapor recortes?" (MACHADO DA SILVA apud HOHLFELDT, MARTINO \& FRANÇA, 2001,. 171).

\section{Referências}

ALLIEZ, Éric. A Assinatura do Mundo: 0 que é a filosofia de Deleuze e Guattari?. Rio de Janeiro: Editora 34, 1995. 
ALLIEZ, Éric. Da impossibilidade da fenomenologia: sobre a filosofia francesa contemporânea. Rio de Janeiro: Editora 34, 1996.

ALLIEZ, Éric. Deleuze: Filosofia virtual. Rio de Janeiro: Editora 34, 1996.

BAUDRILLARD, Jean. A llusão Vital. Rio de Janeiro: Civilização Brasileira, 2001.

BAUDRILLARD, Jean. As Estratégias Fatais. Rio de Janeiro: Rocco.

BAUDRILLARD, Jean. A Sociedade de Consumo. Rio de Janeiro: Elfos, 1995.

BAUDRILLARD, Jean. À Sombra das Maiorias Silenciosas: 0 fim do social e 0 surgimento das massas. São Paulo: Brasiliense, 1994.

BAUDRILLARD, Jean. A Transparência do Mal: Ensaio sobre os Fenômenos Extremos. Campinas: Papirus, 1996.

BAUDRILLARD, Jean. La ilusión del fin: la huelga de los acontecimentos. Barcelona: Anagrama, 1997.

BAUDRILLARD, Jean. 0 Crime Perfeito. Lisboa: Relógio D’Água, 1996.

BAUDRILLARD, Jean. 0 Sistema dos Objetos. São Paulo: Perspectiva, 1997.

BAUDRILLARD, Jean. Para uma crítica da Economia Política do Signo.

BAUDRILLARD, Jean. Simulacros e Simulações.

BAUDRILLARD, Jean. Tela Total: mitoironias da era do virtual e da imagem. Porto Alegre: Sulina, 1997.

BOUGNOUX, Daniel. Introdução às Ciências da Comunicação. Bauru: Edusc, 1999.

COHEN, Jeffrey Jerome. Pedagogia dos monstros: os prazeres e os perigos da confusão de fronteiras. Belo Horizonte: Autêntica, 2000.

CONNOR, STEVEN. Cultura Pós-Moderna: Introdução às Teorias do contemporâneo. São Paulo: Loyola, 1993.
DEBORD, GUY. A sociedade do espetáculo. Rio de Janeiro: Contraponto, 1997.

DEBRAY, Régis. Curso de Midiologia Geral.

DEBRAY, Régis. Manifestos Midiológicos.

DEBRAY, Régis. 0 Estado Sedutor: as revoluções midiológicas do poder. Petrópolis: Vozes, 1994.

DELEUZE, Gilles. Conversações. Rio de Janeiro: Editora 34, 1992.

DELEUZE, Gilles \& GUATTARI, Félix. O Anti-Édipo.

DERRIDA, Jacques. Limited Inc. Campinas: Papirus, 1991.

DERRIDA, Jacques. Structure, Sign and Play in the Discourses of the Human Sciences. In: Writting and Difference.

Chicago: University of Chicago Press, 1978.

DESCAMPS, Christian. As Idéias Filosóficas Contemporâneas na França. Rio de Janeiro: Zahar, 1991.

FeAtherstone, Mike. Cultura de Consumo e PósModernismo. São Paulo: Studio Nobel, 1995.

FOLHA DE SÃO PAULO. Teoria da Comunicação. Juremir Machado da Silva. 1998.

GUATTARI, Félix. O Inconsciente Maquínico: ensaios de esquizoanálise. Campinas: Papirus, 1988.

HARVEY, David. Condição Pós-Moderna. São Paulo: Loyola, 1992.

HOHLFELDT, Antonio, MARTINO, Luiz \& FRANÇA, Vera. Teorias da comunicação: conceitos, escolas e tendências. Petrópolis: Vozes, 2001.

HOUELLEBECQ, Michel. El mundo como supermercado. Barcelona: Anagrama, 2000.

HOUELLEBECQ, Michel. Plataforma.

JEUDY, Henri-Pierre. A Ironia da Comunicação. Porto Alegre: Sulina, 2001. 
JOHNSON, Christopher. Derrida. São Paulo: Editora Unesp, 2001.

LIPOVETSKY, Gilles. O Império do Efêmero: a moda e seu destino nas sociedades modernas. São Paulo: Companhia das Letras, 1989.

LYON, David. Pós-Modernidade. São Paulo: Paulus, 1998.

LYOTARD, Jean-François. A Condição Pós-Moderna. Lisboa: Gradiva, 1989.

MAFFESOLI, Michel. A Conquista do Presente. Rio de Janeiro: Rocco, 1984.

MAFFESOLI, Michel. A Contemplação do Mundo. Porto Alegre: Artes \& Ofícios: 1995.

MAFFESOLI, Michel. A Sombra de Dionísio. Rio de Janeiro: Graal, 1985.

MAFFESOLI, Michel. A Transfiguração do Político: a tribalização do mundo. Porto Alegre: Sulina, 1997.

MAFFESOLI, Michel. A Violência Totalitária: ensaio de antropologia política. Rio de Janeiro: Zahar, 1981.

MAFFESOLI, Michel. Dinâmica da Violência. São Paulo: Vértice, 1987.

MAFFESOLI, Michel. Elogio da Razão Sensível. Petrópolis: Vozes, 1998.

MAFFESOLI, Michel. Lógica da dominação. Rio de Janeiro: Zahar, 1978.

MAFFESOLI, Michel. No Fundo das Aparências. Petrópolis: Vozes, 1996.

MAFFESOLI, Michel. O Conhecimento Comum. São Paulo: Brasiliense, 1988.

MAFFESOLI, Michel. 0 Tempo das Tribos: 0 declínio do individualismo nas sociedades de massa. Rio de Janeiro: Forense-Universitária, 1987.

MAFFESOLI, Michel. Sobre o Nomadismo: vagabundagens pós-modernas. Rio de Janeiro: Record, 2001.

MORIN, Edgar, BAUDRILLARD, Jean \& MAFFESOLI,
Michel. A Decadência do Futuro e a Construção do Presente. Florianópolis: Editora da UFSC, 1993.

MORIN, Edgar. Para Sair do Século XX. Rio de Janeiro: Nova Fronteira, 1986.

MORIN, Edgar \& KERN, Anne Brigitte. Terra-Pátria. Porto Alegre: Sulina, 1995.

MORIN, Edgar. As Estrelas: mito e sedução no cinema. Rio de Janeiro: José Olympio, 1989.

PENSAMENTO CRÍTICO VERSUS PENSAMENTO ÚNICO: Le Monde Diplomatique. Madrid: Debate, 1998.

PETERS, Michael. Pós-Estruturalismo e Filosofia da Diferença: Uma Introdução. Belo Horizonte: Autêntica, 2000.

RAMONET, Ignacio. A Tirania da Comunicação. Petrópolis: Vozes, 1999.

RAMONET, Ignacio. Geopolítica do Caos. Petrópolis: Vozes, 1998.

RAMONET, Ignacio. O Pensamento Único. Le Monde Diplomatique. Edição de 17 de dezembro de 1994.

SFEZ, Lucien. A Saúde Perfeita: crítica de uma nova utopia. São Paulo: Unimarco, Loyola, 1996.

SFEZ, Lucien. Crítica da Comunicação. São Paulo: Loyola, 1994.

SOKAL, Alan \& BRICMONT, Jean. Imposturas intelectuais: 0 abuso da ciência pelos filósofos pós-modernos. Rio de Janeiro: Record, 1999.

VIRILIO, Paul. AArte do Motor. São Paulo: Estação Liberdade, 1996.

VIRILIO, Paul. A Bomba Informática. São Paulo: Estação Liberdade, 1999.

VIRILIO, Paul. A Máquina de Visão. Rio de Janeiro: José Olympio, 1995.

VIRILIO, Paul. O Espaço Crítico. Rio de Janeiro: Editora 34, 1993. 
VIRILIO, Paul. Guerra e Cinema. São Paulo: Scritta, 1993.

VIRILIO, Paul. Velocidade e Política. São Paulo: Estação Liberdade, 1996.

WAUGH, Patricia. Postmodernism: Reader. Bristol: Arrowsmith, 1992.

WOLTON, Dominique. Elogio do Grande Público: uma teoria crítica da televisão. São Paulo: Ática, 1996. 